\title{
Appendix to Verbal mismatch in Right-Node Raising
}

\author{
Aoi Shiraishi \\ Université de Paris \\ CNRS, LLF \\ 5, rue Thomas Mann, F-75013 Paris \\ ioaaoi430@gmail.com \\ Philip Miller \\ Université de Paris \\ CLILLAC-ARP \\ 5, rue Thomas Mann, F-75013 Paris \\ philip.miller@univ-paris-diderot.fr
}

\author{
Anne Abeillé \\ Université de Paris \\ CNRS, LLF \\ 5, rue Thomas Mann, F-75013 Paris \\ abeille@linguist.univ-paris-diderot.fr \\ Barbara Hemforth \\ Université de Paris \\ CNRS, LLF \\ 5, rue Thomas Mann, F-75013 Paris \\ barbara.hemforth@linguist.univ-paris- \\ diderot.fr
}

\section{Statistical analysis for English experiment}

The data were analyzed with $\mathrm{R}$ version 3.5.0. Ratings were submitted to a linear mixed effects regression (Baayen 2008) using the lmer-function from the R-package lme4, version 1.1-17 (Bates et al. 2015). We first ran a model to compare RNR variants and verb forms. We used the factor ELLIPSIS type (RNR with verbal mismatch, VP anaphor do so without ellipsis, RNR without mismatch) as a within participant and within items predictor and the factor SYNCRETISM (syncretic, non-syncretic) as a within participant but between items predictor. In addition to random intercepts of items and participants, we included random slopes for ELLIPSIS type for items and for participants. Random slopes for SYNCRETISM were also included for participants. P-values were computed with the lmerTest-package (Kuznetsova et al. 2017), using Satterthwaite approximation of degrees of freedom. Predictors were centered for this model. The VP anaphor do so without ellipsis is the reference condition for ELLIPSIS. Results are presented in Table 1. Following this general model, we compared the experimental conditions to grammatical (Table 2) and ungrammatical (Table 3) controls using treatment coding, meaning that each of the ellipses conditions are compared to the grammatical or ungrammatical control. In these latter models, random slopes for Condition were included for participants but not for items since grammatical/ungrammatical sentences were constructed as separate items.

Table 1 shows an effect of the match and the mismatch conditions which are slightly less acceptable than the VP anaphor do so without ellipsis condition across verb forms. No main effect or interaction was found for SYNCRETISM. A separate model, using the match condition as the reference condition for ELLIPSIS shows that the mismatch condition is slightly but significantly more acceptable than the match condition (Estimate: 0.35263, Std. Error: 0.16804, df: 45.68633, t:2.098, p=0.04142). 
Table 1: Syncretism and Ellipsis type

\begin{tabular}{|l|c|c|c|c|c|}
\hline & Estimate & Std.Error & df & $\mathrm{t}$ value & $\operatorname{Pr}(=|t|)$ \\
\hline General mean for syncretism, no ellipsis & 7.35538 & 0.23217 & 50.14390 & 31.681 & $<2 \mathrm{e}-16 * * *$ \\
syncretism & -0.04649 & 0.21088 & 21.77282 & -0.220 & 0.82758 \\
mismatch & -0.40828 & 0.23560 & 26.83718 & -1.733 & 0.09459. \\
match & -0.76122 & 0.26409 & 22.44132 & -3.973 & $0.00854 * *$ \\
syncretism:mismatch & 0.09851 & 0.44818 & 23.87181 & -0.193 & 0.84845 \\
syncretism:match & -0.10351 & 0.53596 & 24.42637 & -0.344 & 0.73456 \\
\hline
\end{tabular}

Since no main effect or interaction was found including SYNCRETISM, comparisons between experimental items and grammatical and ungrammatical controls were done across syncretic and non-syncretic verbs. Tables 2 and 3 show that match and mismatch RNRs are slightly less acceptable than grammatical controls while sentences with the VP anaphor do so but without ellipsis did not significantly differ from the grammatical controls. All three experimental conditions are significantly more acceptable than ungrammatical controls.

Table 2: Comparison to grammatical controls

\begin{tabular}{|l|c|c|c|c|c|}
\hline & Estimate & Std.Error & df & t value & $\operatorname{Pr}(=|t|)$ \\
\hline grammatical control & 7.9127 & 0.2612 & 57.8251 & 30.289 & $<2 \mathrm{e}-16 * * *$ \\
match & -0.9207 & 0.2500 & 47.9003 & -3.682 & $0.000586 * * *$ \\
mismatch & -0.5793 & 0.2427 & 45.5484 & -2.387 & $0.021221 *$ \\
no ellipsis & -0.1652 & 0.2325 & 47.6163 & -0.710 & 0.480874 \\
\hline
\end{tabular}

Table 3: Comparison to ungrammatical controls

\begin{tabular}{|l|c|c|c|c|c|}
\hline & Estimate & Std.Error & df & t value & $\operatorname{Pr}(=|t|)$ \\
\hline ungrammatical control & 4.6825 & 0.3515 & 58.1483 & 13.323 & $<2 \mathrm{e}-16 * * *$ \\
match & 2.3091 & 0.4012 & 58.6934 & 5.756 & $3.33 \mathrm{e}-07 * * *$ \\
mismatch & 2.6512 & 0.4265 & 58.3766 & 6.216 & $5.86 \mathrm{e}-08 * * *$ \\
no ellipsis & 3.0656 & 0.4088 & 59.2380 & 7.498 & $3.79 \mathrm{e}-10 * * *$ \\
\hline
\end{tabular}

\section{Glosses of the examples of the French materi- als}

(22) a. C'est le traitement automatique du langage, qui a pu, et It's the processing automatic of language, which has could, and qui va encore bouleverser le courrier électronique en facilitant which will further upset the mail electronic by facilitating la traduction. the translation.

'It is automatic language processing, which has been able to, and will further revolutionize e-mail by making translation easier.'

b. C'est le traitement automatique du langage qui a, et qui It's the processing automatic of language, which has, and which 
va encore bouleverser le courrier électronique en facilitant la will further upset the mail electronic by facilitating the traduction.

translation.

'It is automatic language processing, which has, and which will further revolutionize e-mail by making translation easier.'

c. C'est le traitement automatique des langues qui a bouleversé It's the processing automatic of language, which has upset le courrier électronique, et qui va encore le bouleverser en the mail electronic, and which will further it upset by facilitant la traduction. facilitating the translation.

'It is automatic language processing, which has revolutionized e-mail, and which will further upset it by making translation easier.'

(23) a. Quelques électeurs auront bientôt, ou ont peut-être déjà rejoint Some voters will.have soon, or have perhaps already joined le centre. the center.

'Some voters will soon have, or may have already joined the center.'

b. Quelques électeurs vont bientôt, ou ont peut-être déjà rejoint le Some voters will soon, or have perhaps already joined the centre. center.

'Some voters will soon, or may have already joined the center.'

c. Quelques électeurs vont bientôt rejoindre le centre, ou l' ont peut-être Some voters will soon join the center, or it have perhaps déjà rejoint. already joined.

'Some voters will soon join the center, or may have already joined it'

(24) a. Les alpinistes n' ont malheureusement pas encore gravi le The mountaineers NEG have unfortunately NEG yet climbed the sommet avant la nuit. summit before the night.

'The mountaineers have unfortunately not climbed the summit before dark.'

b. *Les alpinistes n' ont malheureusement pas encore gravir le The mountaineers NEG have unfortunately NEG yet climb the sommet avant la nuit. summit before the night.

\section{Statistical analysis for French experiment}

Data analysis was done using the same statistical models as before. Just as for the experiment on RNR in English, we first ran a model to compare RNR variants and 
verb forms. ELLIPSIS type (RNR with verbal mismatch, without ellipsis, RNR without mismatch) as a within participant and within items predictor and SYNCRETISM ( \pm syncretic) as a within participant but between items predictor. In addition to random intercepts of items and participants, we included random slopes for ELLIPSIS type for items and for participants. Random slopes for SYNCRETISM were also included for participants. P-values were computed with the lmerTest-package (Kuznetsova et al. 2017), using Satterthwaite approximation of degrees of freedom. Predictors were centered for this model. The NO ELLIPSIS condition is the reference condition for ELLIPSIS. To avoid non-convergence problems, we used the opimx optimizer and we excluded correlations of random intercepts and slopes (Nash \& Varadhan 2011; Nash 2014; Bates et al. 2015).

Results are presented in (Table 4). Following this general model, we compared the experimental conditions to grammatical (Table 5) and ungrammatical (Table 6) controls using treatment coding, meaning that each of the ellipses conditions is compared to the grammatical or ungrammatical control. In these latter models, random slopes for Condition were included for participants but not for items since grammati$\mathrm{cal} /$ ungrammatical sentences were constructed as separate items.

Table 4 shows no significant effects of the match condition. The RNR-MISMATCH condition is however significantly less acceptable than NO ELLIPSIS. A model using RNR-MATCH as reference category shows that the RNR-MISMATCH condition is marginally less acceptable (Est. $=-0.38770$, Std.Error=0.19347, $\mathrm{df}=16.95952, \mathrm{p}=.0613$ ). As for English, no significant main effect or interaction was found for SYNCRETISM.

Table 4: Syncretism and Ellipsis type.

\begin{tabular}{|l|c|c|c|c|c|}
\hline & Estimate & Std.Error & df & t value & $\operatorname{Pr}(=|t|)$ \\
\hline (Intercept/General mean) & 7.300089 & 0.322840 & 46.830579 & 22.612 & $<2 \mathrm{e}-16^{* * *}$ \\
syncretism & -0.006964 & 0.379385 & 24.534625 & -0.018 & 0.9855 \\
mismatch & -0.822061 & 0.344024 & 22.314506 & -2.390 & $0.0257 *$ \\
match & -0.425910 & 0.357736 & 22.249025 & -1.191 & 0.2464 \\
syncretism:mismatch & 0.321799 & 0.662566 & 20.840145 & 0.486 & 0.6323 \\
syncretism:match & -0.103954 & 0.685181 & 20.237625 & -0.152 & 0.8809 \\
\hline
\end{tabular}

Comparisons of experimental items to grammatical and ungrammatical controls were done across syncretic and non-syncretic verbs because no main effect or interaction was found including SYNCRETISM. Tables 2 and 3 show that match and mismatch RNRs are slightly less acceptable than grammatical controls while sentences without ellipsis did not significantly differ from the grammatical controls. All three experimental conditions are significantly more acceptable than ungrammatical controls.

Table 5: Comparison to grammatical controls

\begin{tabular}{|l|c|c|c|c|c|}
\hline & Estimate & Std.Error & $\mathrm{df}$ & $\mathrm{t}$ value & $\operatorname{Pr}(=|t|)$ \\
\hline grammatical control & 9.3308 & 0.2797 & 58.1261 & 33.359 & $<2 \mathrm{e}-16 * * *$ \\
match & -2.5031 & 0.3676 & 55.6231 & -6.809 & $7.36 \mathrm{e}-09 * * *$ \\
mismatch & -2.5163 & 0.3655 & 57.7606 & -6.885 & $4.66 \mathrm{e}-09 * * *$ \\
no ellipsis & -1.7039 & 0.3083 & 65.2294 & -5.527 & $6.13 \mathrm{e}-07 * * *$ \\
\hline
\end{tabular}


Table 6: Comparison to ungrammatical controls

\begin{tabular}{|l|c|c|c|c|c|}
\hline & Estimate & Std.Error & df & t value & $\operatorname{Pr}(=|t|)$ \\
\hline ungrammatical control & 3.2821 & 0.4326 & 53.8822 & 7.586 & $4.66 \mathrm{e}-10 * * *$ \\
match & 3.5361 & 0.5377 & 55.4885 & 6.576 & $1.80 \mathrm{e}-08 * * *$ \\
mismatch & 3.5396 & 0.5011 & 52.1992 & 7.064 & $3.84 \mathrm{e}-09 * * *$ \\
no ellipsis & 4.3523 & 0.5386 & 54.4006 & 8.081 & $6.94 \mathrm{e}-11 * * *$ \\
\hline
\end{tabular}

\section{References}

Baayen, R. Harald. 2008. Analyzing linguistic data: A practical introduction to statistics using $R$. Cambridge: Cambridge University Press.

Bates, Douglas, Martin Maechler, Ben Bolker \& Steve Walker. 2015. Fitting linear mixed-effects models using lme4. Journal of Statistical Software 67. 1-48.

Kuznetsova, Alexandra, Per B. Brockhoff \& Rune H. B. Christensen. 2017. ImerTest package: Tests in linear mixed effects models. Journal of Statistical Software 82. $1-26$.

Nash, John C. 2014. On best practice optimization methods in R. Journal of Statistical Software 60. 1-14. https://www. jstat soft.org/index.php/jss/ article/view/v060i02/v60i02.pdf.

Nash, John C. \& Ravi Varadhan. 2011. Unifying optimization algorithms to aid software system users: optimx for R. Journal of Statistical Software 43. 114. httpshttps://www.jstatsoft.org/index.php/jss/article/ view/v043i09/v43i09.pdf. 